\title{
Erratum to: Is cognitive stability in Parkinson's disease a predictable phenomenon? A 5-year follow-up study
}

\author{
Maria Elena Di Battista ${ }^{1}$ Alfonso Rubino ${ }^{1} \cdot$ Marcella Valente $^{1} \cdot$ Patrizia Giustini $^{1}$. \\ Nicola Vanacore ${ }^{2} \cdot$ Giuseppe Meco $^{1}$
}

Published online: 6 November 2015

(C) Springer-Verlag Wien 2015

\section{Erratum to: J Neural Transm}

\section{DOI 10.1007/s00702-015-1440-2}

Unfortunately, there is a mistake in the affiliation of the coauthor Nicola Vanacore in the original version of the article. The correct affiliation should be

National Centre of Epidemiology, National Institute of Health, Rome, Italy.

The online version of the original article can be found under doi:10.1007/s00702-015-1440-2.

\section{Giuseppe Meco}

giuseppe.meco@uniroma1.it

1 Department of Neurology and Psychiatry, University of Rome "Sapienza", C.I.M.S. Centro Interdipartimentale Malattie Sociali, Rome, Italy

2 National Centre of Epidemiology, National Institute of Health, Rome, Italy 